\title{
Degummed crude canola oil supplementation affects fat depot melting points in purebred and first-cross Merino sheep
}

\author{
Aaron Ross Flakemore ${ }^{1}$, Peter David McEvoy ${ }^{1}$, Razaq Oladimeji Balogun ${ }^{2}$, \\ Bunmi Sherifat Malau-Aduli ${ }^{3}$, Peter Nichols ${ }^{4}$, Aduli Enoch Othniel Malau-Aduli ${ }^{1,5}$, * \\ ${ }^{1}$ Animal Science and Genetics, Tasmanian Institute of Agriculture, School of Land and Food, Faculty of Science, Engineering and \\ Technology, University of Tasmania, Private Bag 54 Sandy Bay, Hobart, Tasmania 7001, Australia \\ ${ }^{2}$ Coprice Feeds, PO Box 104 Cobden, Victoria 3266, Australia \\ ${ }^{3}$ School of Medicine and Dentistry, Faculty of Medicine, Health and Molecular Sciences, James Cook University, Townsville, \\ Queensland 4811, Australia \\ ${ }^{4}$ Commonwealth Scientific and Industrial Research Organisation Food Futures Flagship, Division of Marine and Atmospheric Research, \\ G.P.O. Box 1538, Hobart, Tasmania 7001, Australia \\ ${ }^{5}$ School of Veterinary and Biomedical Sciences, Faculty of Medicine, Health and Molecular Sciences, James Cook University, \\ Townsville, Queensland 4811, Australia
}

\section{Email address:}

Aduli.MalauAduli@utas.edu.au (A. E. O. Malau-Aduli); aduli.malauaduli@jcu.edu.au (A. E. O. Malau-Aduli)

\section{To cite this article:}

Aaron Ross Flakemore, Peter David McEvoy, Razaq Oladimeji Balogun, Bunmi Sherifat Malau-Aduli, Peter Nichols, Aduli Enoch Othniel Malau-Aduli. Degummed Crude Canola Oil Supplementation Affects Fat Depot Melting Points in Purebred and First-Cross Merino Sheep. Animal and Veterinary Sciences. Vol. 2, No. 3, 2014, pp. 75-80. doi: 10.11648/j.avs.20140203.14

\begin{abstract}
The objective of this study was to test the hypothesis that degummed crude canola oil (DCCO) will lower fat melting points (FMP) of both visceral and subcutaneous fats in lambs. Twenty-four lambs comprising purebred and firstcross Merino progeny from Dorset, White Suffolk and Merino sires mated to purebred Merino ewes were supplemented with varying levels of DCCO over a nine-week period. The experimental treatment groups were: Control (1 kg plain wheatbased pellets only), Medium (500g plain wheat-based pellets $+500 \mathrm{~g}$ wheat-based pellets containing DCCO), and High ( $1 \mathrm{~kg}$ wheat-based pellets containing DCCO at a concentration of $50 \mathrm{ml} / \mathrm{kg}$ ) supplementation levels. The flock comprised eight wether and ewe lambs per treatment. However, at the end of the trial, four Merino ewes were retained in the flock for breeding purposes, while the remaining twenty lambs were slaughtered in a commercial abattoir. Visceral fat samples were taken from the kidney region and subcutaneous fat samples were taken from the Longissimus dorsi muscle. FMP was determined using temperature slip point methodology in the laboratory. DCCO had significant effects on the FMP of both subcutaneous $(\mathrm{p}$ 0.0002) and visceral $(\mathrm{p}<0.0001)$ fats, with the lowest FMP achieved at high levels of supplementation in both fat depots. Significant sire breed differences $(\mathrm{p}<0.0001)$ were also detected in which Dorset-sired progeny had the highest melting points in both fat depots. The results of this study indicate that within fat depots, DCCO supplementation produced softer fats with lower melting points, suggesting potentially healthier fats likely to contain higher levels of unsaturated fatty acids.
\end{abstract}

Keywords: Degummed Crude Canola Oil, Fat Melting Point, Subcutaneous Fat, Visceral Fat, Sire Breed

\section{Introduction}

Fat melting point (FMP) is the key determinant of fat hardness or softness. The lower the melting point, the softer the fat and vice-versa. From a production viewpoint, hard fats on animal carcasses present a processing challenge in the boning room of meat processing plants $[1,2]$. Softer fats are preferable as they are easier to trim or remove by hand, thereby improving workplace occupational health and safety conditions. Nutritionally, softer fats contain higher levels of unsaturated fatty acids, whereas harder fats contain higher levels of saturated fatty acids [3-5]. Unsaturated fatty acids are preferred in human diets as they aid in the prevention of rheumatoid inflammation and 
cardiovascular diseases [6]. However, from a meat quality perspective, softer fats may be more prone to oxidation compared to harder fats, thereby initiating the onset of rancidity in meat, which can have subsequent adverse impacts on shelf life, colour and flavour [3-5].

Of late, there is increasing interest in the inclusion of lipids as alternative, energy-dense supplementary feed sources in the diet of ruminants [7]. Published literature has established that when lipids are included in sheep diets, they can have sequential effects on fatty acid compositions [8-12] and therefore, the melting points of fats. However, there is currently a knowledge gap on the use of degummed crude canola oil (DCCO) as a high energy, unsaturated fatty acid supplementary feed source in sheep diets and its impact on fat melting point.

In this study, we tested the hypothesis that supplementation of sheep with degummed crude canola oil lowers the melting points of both visceral and subcutaneous fat depots. The objective of this study was to assess the impact of dietary DCCO supplementation on the melting points of visceral and subcutaneous fat depots in genetically divergent sheep.

\section{Materials and Methods}

\subsection{Animals and Management}

This experiment was conducted at the University of Tasmania Farm, Cambridge, Hobart, Tasmania, Australia. All procedures were approved by the University of Tasmania Animal Ethics Committee and conducted in accordance with the 1993 Tasmanian Animal Welfare Act and the 2004 Australian Code of Practice for the Care and Use of Animals for Scientific Purposes.

Twenty-four purebred and first-cross lambs, weaned at six months of age, were subjected to a nine-week feeding trial using 3 levels of DCCO supplementation: Control $(1 \mathrm{~kg}$ plain wheat-based pellets only), medium (500g plain wheat-based pellets $+500 \mathrm{~g}$ wheat-based pellets containing DCCO), and high (1 kg wheat-based pellets containing DCCO at a concentration of $50 \mathrm{ml} / \mathrm{kg}$ ). Lambs were sired by Dorset, White Suffolk and Merino rams crossed with pure bred Merino ewes, consisting of eight lambs per genotype comprising four ewes and four wethers. All supplementation levels were replicated within each genotype and sex. During the trial, all experimental animals were given ad libitum access to lucerne hay and water. The nutritional composition of the experimental diets is given in Table 1. Four Merino ewes were retained in the flock for breeding purposes, while the remaining twenty lambs were slaughtered at a commercial abattoir. Visceral fat samples from the slaughtered animals were taken from the kidney region and subcutaneous fat from the Longissimus dorsi muscle between the $12^{\text {th }}-13^{\text {th }}$ rib interface.

\subsection{Determination of Fat Melting Points}

Fat melting points (FMP) were determined in triplicates using five grams of fat from each depot from each animal. These fat samples were melted in an oven set at $105^{\circ} \mathrm{C}$ for 1 hour and drawn up into open-ended capillary tubes using air suction. Samples were placed in a fridge to enable the fats to solidify. Prior to analysis, sub-samples were removed from refrigeration, the fat level marked with an indelible pen on the capillary tube and attached to a $100^{\circ} \mathrm{C}$ thermometer, measuring at $1{ }^{\circ} \mathrm{C}$ unit intervals. This was suspended vertically, submerged in a beaker filled with $80 \mathrm{~mL}$ of distilled water and placed on a hot plate set at a medium heating level. The submerged capillary tube was then observed, with the slip point of the fat defined as the temperature at which the lipid was observed to have melted and 'slipped' within the capillary tube. The temperature at which this occurred was then recorded.

Table 1. Composition of experimental diets as \% of dry matter

\begin{tabular}{llll}
\hline Component & $\begin{array}{l}\text { Crude degummed } \\
\text { canola oil- enriched } \\
\text { pellets (50ml/kg) }\end{array}$ & $\begin{array}{l}\text { Basal (Plain) } \\
\text { wheat-based } \\
\text { pellets }\end{array}$ & $\begin{array}{l}\text { Lucerne } \\
\text { hay }\end{array}$ \\
\hline $\begin{array}{l}\text { Dry Matter } \\
\text { Crude Protein }\end{array}$ & 91.8 & 90.9 & 85.6 \\
$\begin{array}{l}\text { Acid Detergent } \\
\text { Fiber }\end{array}$ & 12.7 & 10.4 & 17.0 \\
$\begin{array}{l}\text { Neutral Detergent } \\
\text { Fiber }\end{array}$ & 20.0 & 9.0 & 44.9 \\
$\begin{array}{l}\text { Total Digestible } \\
\text { Nutrients }\end{array}$ & 75.7 & 21.1 & 55.2 \\
$\begin{array}{l}\text { Ash } \\
\text { Crude Fat }\end{array}$ & 9.7 & 72.0 & 55.4 \\
\hline
\end{tabular}

\subsection{Statistical Analysis}

Statistical analyses of data were performed using the Statistical Analysis System (SAS 2009). Summary statistics of fat melting points by sire breed, sex and supplementation level were computed within each fat depot as part of the data editing procedure to identify any possible outliers using PROC MEANS. The General linear model procedure (PROC GLM) in SAS was then utilized for multi-trait analysis of variance fitting the fixed effects of sire breed, sex, supplementation level and their second-order interactions on subcutaneous and visceral depot fat melting points. Non-significant interactions were dropped from the final model. Pairwise comparisons and mean separations were carried out using Tukey's test at a minimum threshold of $\mathrm{p}<0.05$ level of significance.

\section{Results}

\subsection{Effect of DCCO Level, Sire Breed and Sex on Subcutaneous and Visceral Fat Depot Melting Points}

Within fat depots, level of supplementation with DCCO had significant effects on the melting points of both subcutaneous $(\mathrm{p}<0.0002)$ and visceral $(\mathrm{p}<0.0001)$ fats (Table 2$)$. As shown in Table 2, the lowest melting point for subcutaneous fat was observed in the High level of supplementation $\left(41.6 \pm 0.3^{\circ} \mathrm{C}\right)$ 
compared to the Control $\left(42.0 \pm 0.2^{\circ} \mathrm{C}\right)$ and Medium $\left(42.0 \pm 0.4^{\circ} \mathrm{C}\right)$ supplementation levels. Similarly, visceral FMP was lower at $H i g h$ supplementation $\left(45.3 \pm 0.4^{\circ} \mathrm{C}\right)$ compared to Control $\left(46.0 \pm 0.2^{\circ} \mathrm{C}\right)$ and Medium $\left(46.4 \pm 0.4^{\circ} \mathrm{C}\right)$ supplementation levels.

Fat melting points were also significantly influenced by sire breed $(\mathrm{p}<0.0001)$ in both fat depots as depicted in Table 2. Fats from lambs sired by Dorset recorded the highest melting points for both subcutaneous fat $\left(42.8 \pm 0.2^{\circ} \mathrm{C}\right)$ compared to White Suffolk $\left(41.0 \pm 0.3^{\circ} \mathrm{C}\right)$ and Merino $\left(41.8 \pm 0.4^{\circ} \mathrm{C}\right)$, and visceral fat $\left(46.9 \pm 0.2^{\circ} \mathrm{C}\right)$ compared to White Suffolk $\left(45.2 \pm 0.2^{\circ} \mathrm{C}\right)$ and Merino $\left(45.7 \pm 0.5^{\circ} \mathrm{C}\right)$. There were no significant differences $(p>0.05)$ in melting points between ewes and wethers for both subcutaneous and visceral fat depot sites.

\subsection{Effect of Level of DCCO Supplementation, Sire Breed and Sex Interactions on Subcutaneous and Visceral Fat Depot Melting Points}

Sire breed and supplementation interactions were observed to significantly impact the FMP of both subcutaneous $(p<0.0001)$ and visceral $(p<0.0001)$ fat depots (Table 3).

Table 2. Least square means and standard errors (LSM $\pm S E$ ) of subcutaneous and visceral fat depot melting points $\left({ }^{\circ} \mathrm{C}\right)$ of degummed crude canola oil supplemented prime lambs.

\begin{tabular}{lll}
\hline Fixed effect & $\begin{array}{l}\text { Fat depot } \\
\text { Subcutaneous }\end{array}$ & Visceral \\
\hline Level of supplementation & & \\
Control & $42.0 \pm 0.2^{\mathrm{a}}$ & $46.0 \pm 0.2^{a}$ \\
Medium & $42.0 \pm 0.4^{a}$ & $46.4 \pm 0.4^{a}$ \\
High & $41.6 \pm 0.3^{b}$ & $45.3 \pm 0.4^{b}$ \\
p-value & $0.0002^{* * *}$ & $0.0001^{* * *}$ \\
Sire breed & & \\
Dorset & $42.8 \pm 0.2^{a}$ & $46.9 \pm 0.2^{a}$ \\
White Suffolk & $41.0 \pm 0.3^{b}$ & $45.2 \pm 0.2^{b}$ \\
Merino & $41.8 \pm 0.4^{c}$ & $45.7 \pm 0.5^{b}$ \\
p-value & $0.0001^{* * *}$ & $0.0001^{* * *}$ \\
Sex & & \\
Ewe & $41.9 \pm 0.3$ & $46.0 \pm 0.2$ \\
Wether & $41.8 \pm 0.2$ & $45.9 \pm 0.3$ \\
p-value & $0.9752^{n s}$ & $0.7653^{n s}$ \\
\hline
\end{tabular}

Column means within a fixed effect bearing different superscripts significantly differ $(\mathrm{p}<0.05)$. Level of significance: ns not significant $(\mathrm{p}>0.05)$ and $* * *$ Very highly significant $(\mathrm{p}<0.001)$.

There were no significant differences in subcutaneous FMP between treatments within both Dorset and White Suffolk sire breeds. Purebred Merinos exhibited significant differences between treatments - Control $\left(41.17 \pm 0.17{ }^{\circ} \mathrm{C}\right)$ and Medium $\left(43.63 \pm 0.33^{\circ} \mathrm{C}\right)$ levels of supplementation, as well as between Medium and High $\left(41.00 \pm 0.00^{\circ} \mathrm{C}\right)$ levels of supplementation. There were no differences between Control and High supplementation levels for the Merino genotype. Within visceral fat depots, Dorset displayed significant differences between Control $\left(46.22 \pm 0.22^{\circ} \mathrm{C}\right)$ and Medium $\left(47.56 \pm 0.38^{\circ} \mathrm{C}\right)$ levels of supplementation, with no significant differences between Control and High supplementation or between Medium and High supplementation levels. White Suffolk sired progeny displayed results comparable to those of Dorset with significant differences between Control $\left(46.00 \pm 0.45^{\circ} \mathrm{C}\right)$ and Medium $\left(44.67 \pm 0.29^{\circ} \mathrm{C}\right)$ levels of supplementation, with no differences between other interactions. Purebred Merinos exhibited the greatest degree of differences between FMP in all the three supplementation levels; Medium supplementation displayed the highest FMP $\left(48.00 \pm 0.00^{\circ} \mathrm{C}\right)$, followed by Control $\left(45.83 \pm 0.17^{\circ} \mathrm{C}\right)$ and $\operatorname{High}\left(43.00 \pm 0.00^{\circ} \mathrm{C}\right)$.

Supplementation level significantly interacted with sex in both subcutaneous $(\mathrm{p}<0.0001)$ and visceral $(\mathrm{p}<0.0171)$ fat depot melting points (Table 3). Within ewes, subcutaneous FMP decreased significantly between supplementation levels from $42.44 \pm 0.29^{\circ} \mathrm{C}$ in the Control diet, to $42.00 \pm 0.37^{\circ} \mathrm{C}$ and $40.83 \pm 0.29^{\circ} \mathrm{C}$ under Medium and High supplementation levels, respectively. For visceral fat, there were no significant differences between Control $\left(46.22 \pm 0.22^{\circ} \mathrm{C}\right)$ and Medium supplementation in ewes. However, FMP significantly declined under High supplementation $\left(45.50 \pm 0.67^{\circ} \mathrm{C}\right)$. There were no significant differences observed in subcutaneous FMP between treatments within wethers. There were no significant differences in visceral FMP between Controls $\left(45.92 \pm 0.23^{\circ} \mathrm{C}\right)$ compared to either $\operatorname{High}\left(46.67 \pm 0.59^{\circ} \mathrm{C}\right)$ or Medium treatments $\left(45.25 \pm 0.45^{\circ} \mathrm{C}\right)$, FMP between Medium and High supplementation were observed. There were no significant differences $(\mathrm{p}>0.05)$ in melting points for sex and sire breed interactions for either fat depot (Table 3 ).

Table 3. Subcutaneous and visceral fat depot melting points $\left({ }^{\circ} \mathrm{C}\right)$ interactions between sire breed, DCCO supplementation level and sex in prime lambs supplemented with DCCO.

\begin{tabular}{|c|c|c|c|}
\hline Interaction & & $\begin{array}{l}\text { Fat depot } \\
\text { Subcutaneous }\end{array}$ & Visceral \\
\hline \multirow{2}{*}{ Sire } & Supplementation & & \\
\hline & Level & & \\
\hline \multirow{3}{*}{ Dorset } & Control & $43.0 \pm 0.0$ & $46.2 \pm 0.2^{\mathrm{a}}$ \\
\hline & Medium & $42.9 \pm 0.4$ & $47.6 \pm 0.4^{\mathrm{b}}$ \\
\hline & High & $42.3 \pm 0.2$ & $46.8 \pm 0.2^{\mathrm{ab}}$ \\
\hline \multirow{3}{*}{ White Suffolk } & Control & $41.2 \pm 0.2$ & $46.0 \pm 0.5^{\mathrm{a}}$ \\
\hline & Medium & $40.6 \pm 0.4$ & $44.7 \pm 0.3^{\mathrm{b}}$ \\
\hline & High & $41.2 \pm 0.2$ & $45.1 \pm 0.4^{\mathrm{ab}}$ \\
\hline \multirow{3}{*}{ Merino } & Control & $41.2 \pm 0.2^{\mathrm{a}}$ & $45.8 \pm 0.2^{\mathrm{a}}$ \\
\hline & Medium & $43.7 \pm 0.3^{\mathrm{b}}$ & $48.0 \pm 0.0^{\mathrm{b}}$ \\
\hline & High & $41.0 \pm 0.0^{\mathrm{a}}$ & $43.0 \pm 0.0^{\mathrm{c}}$ \\
\hline p-value & & $<0.0001^{* * *}$ & $<0.0001^{* * *}$ \\
\hline \multirow[t]{2}{*}{$\operatorname{Sex}$} & Supplementation Level & & \\
\hline & Control & $42.4 \pm 0.3^{\mathrm{a}}$ & $46.2 \pm 0.2^{\mathrm{a}}$ \\
\hline \multirow[t]{3}{*}{ Ewe } & Medium & $42.0 \pm 0.4^{b}$ & $46.0 \pm 0.4^{\mathrm{a}}$ \\
\hline & High & $40.8 \pm 0.8^{\mathrm{c}}$ & $45.5 \pm 0.7^{b}$ \\
\hline & Control & $41.6 \pm 0.3$ & $45.9 \pm 0.2^{\mathrm{a}}$ \\
\hline \multirow[t]{2}{*}{ Wether } & Medium & $42.0 \pm 0.6$ & $46.7 \pm 0.6^{\mathrm{b}}$ \\
\hline & High & $41.9 \pm 0.2$ & $45.3 \pm 0.5^{\mathrm{ac}}$ \\
\hline p-value & & $<0.0001^{* * *}$ & $0.0171^{*}$ \\
\hline Sire breed & Sex & & \\
\hline
\end{tabular}




\begin{tabular}{llll}
\hline \multirow{2}{*}{ Interaction } & & $\begin{array}{l}\text { Fat depot } \\
\text { Subcutaneous }\end{array}$ & Visceral \\
\hline \multirow{2}{*}{ Dorset } & Ewe & $43.0 \pm 0.1$ & $46.6 \pm 0.3$ \\
& Wether & $42.6 \pm 0.3$ & $47.2 \pm 0.3$ \\
\multirow{2}{*}{ White Suffolk } & Ewe & $40.8 \pm 0.3$ & $45.3 \pm 0.3$ \\
\cline { 2 - 3 } Merino & Wether & $41.2 \pm 0.4$ & $45.0 \pm 0.3$ \\
p-value & Wether & $41.8 \pm 0.4$ & $45.7 \pm 0.5$ \\
\hline
\end{tabular}

Column means within a second-order interaction bearing different superscripts significantly differ $(p<0.05)$. Level of significance: ns not significant $(\mathrm{p}>0.05), *$ significant $(\mathrm{p}<0.05)$ and $* * *$ Very highly significant $(\mathrm{p}<0.001)$.

\section{Discussion}

The results of this study demonstrate that within fat depots, DCCO supplementation has the potential to produce softer fats with lower melting points, particularly at high levels of supplementation. This supports our hypothesis that DCCO supplementation will lower the melting points of both visceral and subcutaneous fat depots in sheep. The resulting fat softness induced by increased supplementation, indicates that fats from lambs supplemented with DCCO would be easier for meat processors to work with, thereby reducing the incidence of work-related injuries. Furthermore, our findings suggest that fats from sheep supplemented with DCCO have the potential to produce higher concentrations of unsaturated fatty acids in edible fats which are beneficial for human health. However, softer fats containing higher concentrations of unsaturated fatty acids may induce meat oxidation [5]. Therefore, it is reasonable to infer that the observed lower melting points with increasing supplementation levels could have subsequent impacts on meat shelf-life, colour and flavour which could adversely affect meat eating quality and tallow-based products.

Previous studies have recognised that dietary unsaturated fats can extensively impact on the fatty acid profiles of ruminants with resultant increases in unsaturated fatty acid content in the adipose tissue [12, 14-16]. The lowering of melting points with increased supplementation levels observed in the present study reflects the aforementioned annotations. However, Bas and Morand-Fehr [17], Busboom et al. [18] and Miller et al. [19] propose that changes in FMP are allied with variances in percentages of the fatty acid $\mathrm{C} 18: 0$, rather than increases in unsaturated fatty acids per se. This may account for the observed lower FMP associated with increased supplementation levels herein. Therefore, given that varying compositions of fatty acids can occur, further research assessing the fatty acid composition of adipose tissues from lambs supplemented with degummed crude canola oil is recommended.

The research findings of Malau-Aduli et al. [20]; Pitchford et al. [21] and Siebert et al. [22] demonstrated that ruminant FMP can be affected by sire breed. The findings herein, support such established observations. The differences displayed between sire breeds in the current research indicates that first-cross progeny from Dorset sires are prone to developing fats with high FMP compared to other genotypes, regardless of anatomical site of deposition. This suggests that potentially higher levels of saturated fatty acids which are less susceptible to oxidation and more favourable to maintaining shelf-life stability and meat quality attributes in tallow-based products for longer periods, are in abundance in Dorset-sired progeny than in the other genotypes studied. Conversely, the relatively lower melting points displayed in Merino and White Suffolk genotypes indicates higher proportions of unsaturated fatty acids compared to Dorset. These observations were unanticipated, particularly in Merinos, given previously published literature by Fogarty et al. [23] and Wiese et al. [24] to the effect that the Merino is a comparatively late-maturing breed than others, with a predisposition for leanness, suggesting indirectly that higher FMP would be observed amongst the purebred Merino studied. Nevertheless, given the fact that fat deposition increases with animal age [25], it can be argued that purebred Merino may well have exhibited its propensity for leanness, and hence, displayed higher melting points than the Dorset meat breed if the animals were older.

Variations in FMP between treatments within genotypes in the present study indicate that the deposition of fatty acid types in subcutaneous and visceral fat depots varies between genotypes. The observed variations in subcutaneous and visceral fat depot melting points in Merinos under varying levels of DCCO supplementation suggests that this genotype is likely more susceptible to changes in dietary fatty acid composition compared to other genotypes. However, the lack variation in subcutaneous FMP between treatments within Dorset and White Suffolk lambs indicates that subcutaneous fat depots are either less susceptible to influxes of unsaturated fatty acids in their diet, or that subcutaneous fat depots are later maturing in these genotypes compared to the Merino. This points to the likelihood that differing levels of dietary fatty acids are more readily diverted into other metabolic processes between genotypes, such as incorporation into the phospholipid component of muscles [26], or intramuscular fat content [27]. However, this requires further investigation.

It is understood that the fats of uncastrated male lambs (rams) are softer than those of castrated lambs (wethers) [28] and females (ewes) [29, 30], thereby exhibiting lower melting points with higher concentrations of unsaturated fatty acids. In the present study, a lack of significant difference between the sexes in terms of fixed effects or sire breed interactions indicates negligible differences between the sexes regarding fat stability and meat quality. The observed lack of sex differentiation supports Warriss [31] who reported that castration eliminates the anabolic effects of male sex hormones in wethers, which in turn, results in wethers producing a carcass composition similar to those of ewes. However, the results herein demonstrated that within sexes, FMP can be influenced by the inclusion of degummed crude canola oil in the diet, thereby affecting meat quality parameters. 


\section{Conclusion}

This study demonstrates that within fat depots, degummed crude canola oil supplementation has the potential to produce softer fats with lower melting points, particularly at high levels of supplementation. These fats would be easier for meat works employees to process, thereby reducing the potential for work-related injuries to occur. Furthermore, the observed lower melting points indicate that there are possibly higher proportions of unsaturated fatty acids beneficial for human health. This study also demonstrates clear and identifiable differences in FMP between sire breeds, and that supplementation with DCCO can affect FMP within sire breed. This will enable prime lamb producers to make informed decisions regarding the use of DCCO in their flock. However, given the potential for variation in fatty acid composition, future work should involve a fatty acid analysis, assessing the nutritional content of fats and meat cuts from sheep fed degummed crude canola oil. This is the next step we are taking in our laboratory to unravel the fatty acid composition of adipose and muscle tissues of lambs supplemented with varying levels of DCCO.

\section{Acknowledgements}

The Australian Wool Education Trust (AWET) provided an honours scholarship to support the wool aspects of this study. The authors gratefully acknowledge this financial contribution by AWET. The authors are also grateful to CopRice Feeds, Cobden, Victoria, Australia for collaborative research support of pelleted feed production. We acknowledge with gratitude that the senior author was a $\mathrm{PhD}$ scholarship recipient of the University of Tasmania (UTAS) Australian Postgraduate Award (APA) through the Commonwealth Government of Australia.

\section{Competing Interests}

The authors declare that they have no competing interests.

\section{References}

[1] Smith SB, Yang AJ, Larsen TW, Tume RK: Positional analysis of triacylglycerols from bovine adipose tissue lipids varying in degree of unsaturation. Lipids 1998, 33:197-207.

[2] Yang A, Larsen TW, Smith SB, Tume RK: Delta (9) desaturase activity in bovine subcutaneous adipose tissue of different fatty acid composition. Lipids 1999, 34:971-978.

[3] Webb EC, O'Neill HA: The animal fat paradox and meat quality. Meat Sci 2008, 80:28-36.

[4] Wood JD, Enser M, Fisher AV, Nute GR, Sheard PR, Richardson RI, Hughes SI, Whittington FM: Fat deposition, fatty acid composition and meat quality: A review. Meat Sci 2008, 78:343-358.

[5] Wood JD, Enser M, Fisher AV, Nute GR, Whittington FM,
Richardson RI: Effects of diets on fatty acids and meat quality. Options Mediterraneennes Serie A, Seminaires Mediterraneens 2005, 133-141.

[6] Calder PC: n-3 polyunsaturated fatty acids, inflammation, and inflammatory diseases. Am J Clin Nutr 2006, 83:1505S1519S.

[7] Hess BW, Moss GE, Rule DC: A decade of developments in the area of fat supplementation research with beef cattle and sheep. J Anim Sci 2008, 86:E188-204.

[8] Bessa RJB, Portugal PV, Mendes IA, Santos-Silva J: Effect of lipid supplementation on growth performance, carcass and meat quality and fatty acid composition of intramuscular lipids of lambs fed dehydrated lucerne or concentrate. Livest Prod Sci 2005, 96:185-194.

[9] Mills SC, Cook LJ, Scott TW, Nestel PJ: Effect of dietary0fat supplementation on compositional and positional distribution of fatty-acids in ruminant and porcine glycerides. Lipids 1976, 11:49-60.

[10] Santos-Silva J, Mendes IA, Portugal PV, Bessa RJB: Effect of particle size and soybean oil supplementation on growth performance, carcass and meat quality and fatty acid composition of intramuscular lipids of lambs. Livest Prod Sci 2004, 90:79-88.

[11] Szumacher-Strabel M, Cieslak A, Nowakowska A, Potkanski A: Feeding plant and fish oils to improve polyunsaturated fat concentrations in intramuscular, perirenal and subcutaneous lambs' fat. Zuchtungskunde 2009, 81:133-140.

[12] Wachira AM, Sinclair LA, Wilkinson RG, Enser M, Wood JD, Fisher AV: Effects of dietary fat source and breed on the carcass composition, n-3 polyunsaturated fatty acid and conjugated linoleic acid content of sheep meat and adipose tissue. Brit J Nutr 2002, 88:697-709.

[13] SAS Institute: Statistical Analysis System. In SAS Institute, Version 9.2 Cary, NC, USA; 2009.

[14] Golshan-Zoroofi M, Shahryar HA, Chekaniazar V, Chekaniazar S: Effect of different oil sources on muscle fatty acid composition and serum lipoproteins levels in Sarabi beef steer. Int J Anim Vet Adv 2011, 3:379-385.

[15] Peng YS, Brown MA, Wu JP, Liu Z: Different oilseed supplements alter fatty acid composition of different adipose tissues of adult ewes. Meat Sci 2010, 85:542-549.

[16] Radunz AE, Wickersham LA, Loerch SC, Fluharty FL, Reynolds CK, Zerby HN: Effects of dietary polyunsaturated fatty acid supplementation on fatty acid composition in muscle and subcutaneous adipose tissue of lambs. J Anim Sci 2009, 87:4082-4091.

[17] Bas P, Morand-Fehr P: Effect of nutritional factors on fatty acid composition of lamb fat deposits. Livest Prod Sci 2000, 64:61-79.

[18] Busboom JR, Miller GJ, Field RA, Crouse JD, Riley ML, Nelms GE, Ferrell CL: Characteristics of fat from heavy ram and wether lambs. J Anim Sci 1981, 52:83-92.

[19] Miller GJ, Kunsman JE, Field RA: Characteristics of soft subcutaneous fat in ram lambs fed corn and corn-silage diets. J Food Sci 1980, 45:279-\&. 
[20] Malau-Aduli AEO, Edriss MA, Siebert BD, Bottema CDK, Pitchford WS: Breed differences and genetic parameters for melting point, marbling score and fatty acid composition of lot-fed cattle. J Anim Physiol Anim Nutr 2000, 83:95-105.

[21] Pitchford WS, Deland MPB, Siebert BD, Malau-Aduli AEO, Bottema CDK: Genetic variation in fatness and fatty acid composition of crossbred cattle. J Anim Sci 2002, 80:28252832 .

[22] Siebert BD, Deland MP, Pitchford WS: Breed differences in the fatty acid composition of subcutaneous and intramuscular lipid of early and late maturing, grain-finished cattle. Aust J Agric Res 1996, 47:943-952.

[23] Fogarty NM, Safari E, Taylor PJ, Murray W: Genetic parameters for meat quality and carcass traits and their correlation with wool traits in Australian Merino sheep. Aust J Agric Res 2003, 54:715-722.

[24] Wiese SC, Pethick DW, Milton JTB, Davidson RH, McIntyre BL, D'Souza DN: Effect of teeth eruption on growth performance and meat quality of sheep. Aust J Exp Agric 2005, 45:509-515.

[25] Barwick SA, Thwaites CJ: Sheep carcasses and their appraisal. 1. Characteristics of commercial Australian lamb and mutton. Aust J Exp Agric 1980, 20:32-39.

[26] Doreau M, Bauchart D, Chilliard Y: Enhancing fatty acid composition of milk and meat through animal feeding. Anim Prod Sci 2011, 51:19-29.

[27] McPhee MJ, Hopkins DL, Pethick DW: Intramuscular fat levels in sheep muscle during growth. Aust J Exp Agric 2008, 48:904-909.

[28] Crouse JD, Busboom JR, Field RA, Ferrell CL: The effects of breed, diet, sex, location and slaughter weight on lamb growth, carcass composition and meat flavor. J Anim Sci 1981, 53:376-386.

[29] Horcada A, Beriain MJ, Purroy A, Lizaso G, Chasco J: Effect of sex on meat quality of Spanish lamb breeds (Lacha and Rasa Aragonesa). Anim Sci 1998, 67:541-547.

[30] Treacher T: Effect of animal and nutritional factors and nutrition on lamb meat quality. Cahiers Options Mediterraneennes 2000, 52:75-86.

[31] Warriss PD: Meat science: An introductory text (2nd Ed.); CABI Series, CABI, Wallingford, Oxfordshire, UK; 2009. 